\title{
Seed storage studies in Mesua ferrea L. a medicinal tree of Indo- Malayan region
}

\author{
Mithun V ${ }^{1}$, Pradeep N S ${ }^{1} \&$ P N Krishnan ${ }^{* 1,2}$ \\ ${ }^{1}$ KSCSTE-Malabar Botanical Garden and Institute for Plant Sciences, GA College Post, Kozhikode 673 014, Kerala, India \\ ${ }^{2}$ Present address: Centre for Innovation in Science and Social Action (CISSA), T.C. 15/510, USRA -55, Udarasiromani Road, Thiruvananthapuram \\ 695010 , Kerala, India \\ *Email: peringattulli@gmail.com
}

\section{ARTICLE HISTORY}

Received: 28 March 2021

Accepted: 22 June 2021

Available online: 17 July 2021

\section{KEYWORDS}

Mesua ferrea; viability; storage; moisture loss

\section{ABSTRACT}

This paper, deals with testing the storage and viability of the seeds of Mesua ferrea L. in 5 different storage conditions. Seeds of M. ferrea are recalcitrant in nature and lose viability with a short span 815 days. Of the different conventional methods tried using the polycarbonate bottle and bags, $M$. ferrea seeds retained viability for 150 days with a slow moisture loss from the seeds stored in closed polycarbonate bottles at $10^{\circ} \mathrm{C}$. Here, we have standardised a conventional technique whereby the viability of the seeds can be extended to $150-180$ days by storing the seeds in polycarbonate bottles at $10^{\circ} \mathrm{C}$.

\section{Introduction}

Mesua ferrea L. is a medicinal tree species distributed in Indo-Malaysian region (tropical parts of Sri Lanka, India, Southern Nepal, Burma, Thailand, Indochina, Philippines, Malaysia and Sumatra). The species is an evergreen one going up to $20-30 \mathrm{~m}$ high but is slow-growing. It is commonly known as iron wood tree. The phenolic compounds present in seeds viz. Mesuol $\left(\mathrm{C}_{23} \mathrm{H}_{22} \mathrm{O}_{5}\right)$ and Mesuone $\left(\mathrm{C}_{29} \mathrm{H}_{42} \mathrm{O}_{4}\right)$ have anti-bacterial properties (1) other than glycosides, flavonoids, xanthones, triglycerides and resins. The plant is used as antimicrobial, antibacterial and anti-protozoal (2-4). M. ferrea is also used as an ornamental plant for its crimson coloured newly flushed foliage and flushing occurs in the month of September-October. The newly crimson coloured leaves changes to yellow before the complete development of green colour.

Traditionally, based on their inherent storage potential, seeds have been grouped into two main categories, viz. recalcitrant and orthodox seeds. Recalcitrant seeds have a remarkably short life, particularly when stored in open air. Seeds of many tropical and sub-tropical tree species are characterized with high moisture content on maturation and are intolerant to desiccation and they have named as recalcitrant (5). Storage potential of tree seeds is highly species-specific and large variation has been encountered across the tree species. The desiccation-sensitive recalcitrant seeds are shed from the tree after maturation with high moisture content, high metabolic activity and poor storage potential; it leads to significant challenge for ex-situ conservation through seedgene bank. Though physiological basis of recalcitrant behaviour is not fully understood, there are three general categories of damage that may take place in recalcitrant seeds, ultimately causing loss of viability: (i) mechanical damage, (ii) metabolism-induced damage, and (iii) macromolecular denaturation (6). In storage, the viability and vigour of the seeds not only vary from genera to genera and variety to variety, but it is also regulated by many physical and chemical factors like moisture content, atmospheric relative humidity, temperature, preliminary seed quality, physical and chemical composition of seed, gaseous exchange, storage structure, storage materials etc. The seeds stored in polythene bag or plastic container at low temperatures viability for longer period with seedling vigour in many species so that selecting the appropriate seed storage container and temperature regime is very important $(7,8)$. Seeds of many endemic tree species of Western Ghats of India and North Eastern India will mature before the onset of monsoon and germinate with the onset of monsoon rain.

The flowering process, seed formation, maturation, seed germination and establishment 
are critical phases in the life cycle of any plant which are highly specific to the environmental factors. There are some studies reported in $M$. ferrea related to fruit size variation, germination, seedling fitness and biomass accumulation during early seedling growth $(9,10)$. In the phenology, rainfall, temperature and daylight had influence in leafing, flowering and seed setting of $M$. ferrea but the climate change had not effect in the biomass accumulation, metabolite production and maturity of seeds during the development (11). In this paper, we report the seed storage studies conducted in $M$. ferrea in which the seeds are desiccation sensitive and lose viability within a short period. In natural condition $M$. ferrea seeds lose moisture content at faster rate and they are become non-viable within a period of 8 days.

\section{Materials and Methods}

Mature fruits were collected from the selected trees located at Malabar Botanical Garden and Institute for Plant Sciences campus and Calicut University campus, Kozhikode, Kerala. When the mature fruits starts abscise from the mother plant, is considered as maturity. Fruits were collected by gentle shaking of fruit bearing branches. The fruits were not let fall on the ground to avoid damage. As the seed viability depends on the harvest time the seed collection was made only on maturity of the seeds. The fruits were brought to the laboratory and washed in running tap water for $1 \mathrm{hr}$ to wash the debris and blotted dried using blotting paper. The seeds were then dissected out from the fruits and sterilized with $0.1 \%$ mercuric chloride for 10 min. They were then washed three times with distilled water and dried at room temperature. The dried seeds were used for the experiments.

The following conditions were used for testing the storage and viability of the seeds of $M$. ferrea. Just after harvest the moisture content and the germination percentage were recorded as per the procedure mentioned. Batches of 100 seeds in each treatment were stored in conditions below and the experiments were replicated thrice.

1) Open laboratory conditions $\left(28 \pm 2{ }^{\circ} \mathrm{C} \&\right.$ $65 \% \mathrm{RH}$ ) in plastic trays (OPL)

2) Closed polycarbonate bottles at room temperature. (CPBoRT)

3) Closed polyethene bags (200 gauge) at room temperature (CPBg200RT)

4) Closed polyethene bags (400 gauge) at room temperature (CPBg400RT)

5) Closed polycarbonate bottle at $10{ }^{\circ} \mathrm{C}$ $\left(\mathrm{CPBO} 10^{\circ} \mathrm{C}\right)$

Seed samples were taken every day up to 10 days, 5 days interval up to 60 days later 30 days interval up to 180 days as the case for different treatments and tested for viability by measuring the germination percentage and the moisture content. For germination the seeds were placed in the germination paper, rolled and kept in a plastic tray moistened with distilled water and the tray was covered with the glass plate. These trays were kept in the dark room at $28 \pm 2{ }^{\circ} \mathrm{C}$ (12). Seeds was considered germinated when the radical protruded by about $2 \mathrm{~mm}$ beyond the seed coat.

Moisture content of the seeds at each interval was determined by High Constant Air Owen method according to ISTA rules (13), Seed samples from each treatment were taken out at regular interval and fresh weights were recorded and later dry weights by drying at $130 \pm 1{ }^{\circ} \mathrm{C}$ for 1 hr.

\section{Statistical Analysis}

The data of percentage of moisture content and percentage germination as a function of storage days were analysed statistically following linear regression analysis using the formula $\mathrm{Y}=\mathrm{a}+\mathrm{bx}$. Correlation coefficient " $r$ " have been calculated and the significance as per standard methodology (14).

\section{Results}

Flowering occurs during the month of March- April in $M$. ferrea. Flowers are white in colour with fragrant stamens. 4 sepals, decussate, sub orbicular, persistent and variously enlarged and thickened. Flower opening time ranges from 3:00 am to 4:00 am. The ovary is bilocular with one or two ovules in ovary. The mature fruit contain 1-4 seeds depending upon the abortion of ovules during the early stages of seed development. The fruits when young are elongated and oval with pointed ends. But, on maturity the fruits are round in shape. When the fruit is split open, the seeds are creamy white in colour and on exposure to air the seed coat turns to dark brown. Large number of immature fruits are found fallen on the ground
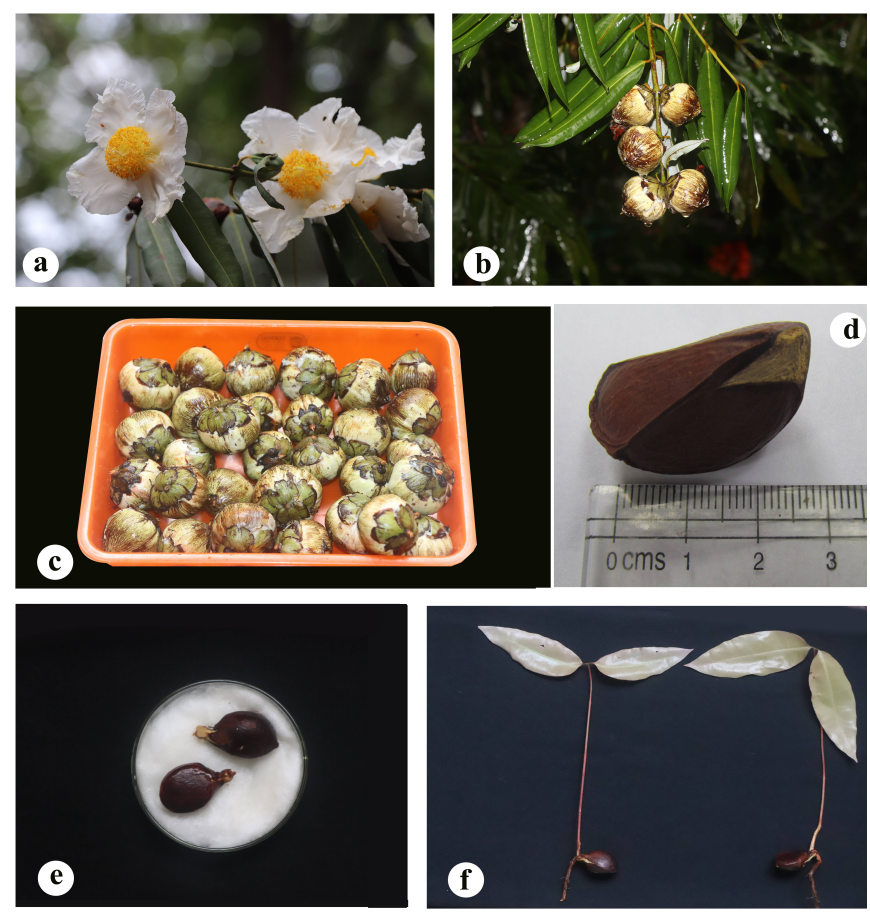

Fig. 1. (a) flowers, (b) fruit bunch, (c) harvested fruits, (d) extracted seeds (e) germinated seeds and (f) developed seedlings. 
attacked by insects. Fig. 1 shows the (a) flowers, (b) fruit bunch, (c) harvested fruits, (d) extracted seeds (e) germinated seeds and (f) developed seedlings.

In general, germination percentage and moisture content (MC) of the $M$. ferrea seeds decreased with the increasing days of storage. The highest germination (100\%) was on the first day of the storage in all the cases (Fig. 2-6) later the decrease was varying with the treatment. During

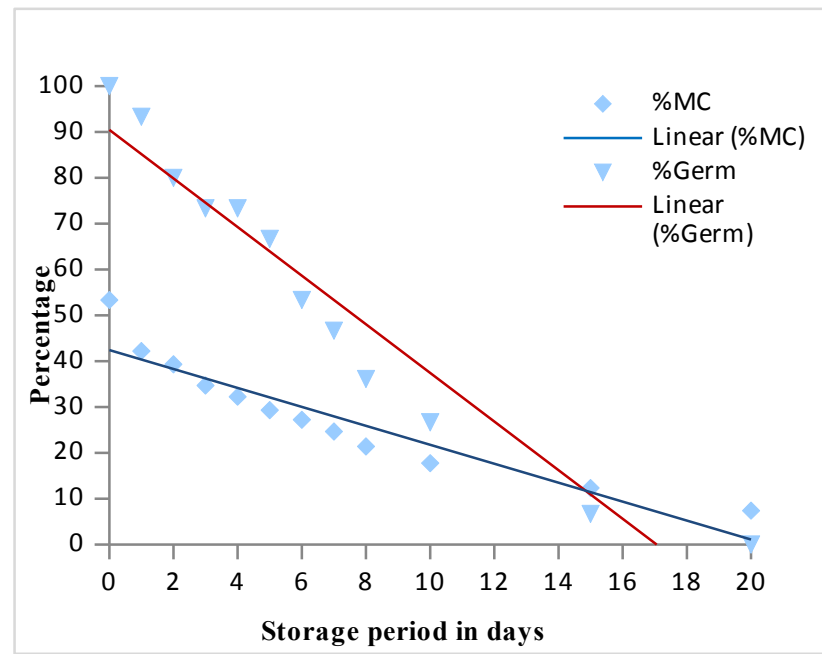

Fig. 2. Open laboratory conditions $\left(28 \pm 2{ }^{\circ} \mathrm{C} \& 65 \% \mathrm{RH}\right)$ in plastic trays (OPL).

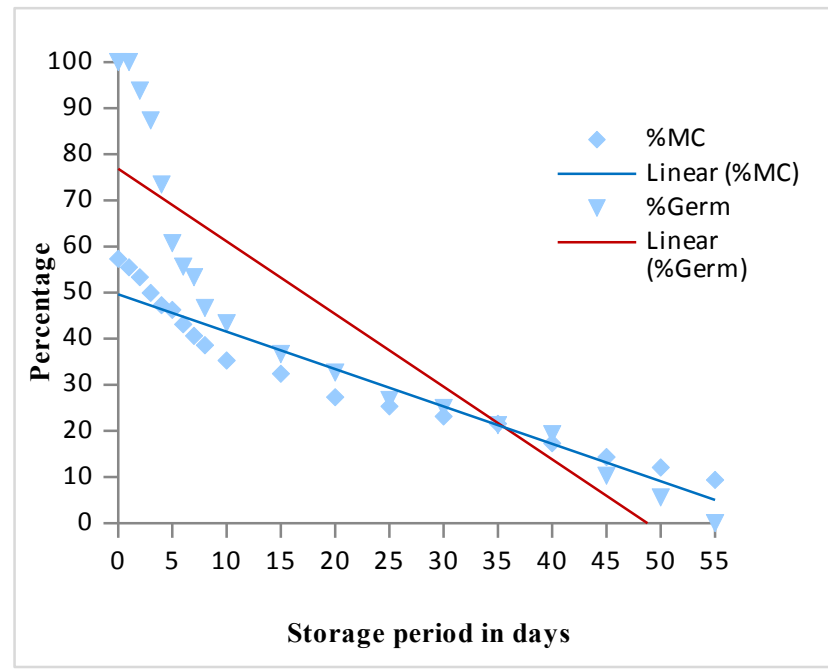

Fig. 3. Closed polycarbonate bottles at room temperature (CPBoRT).

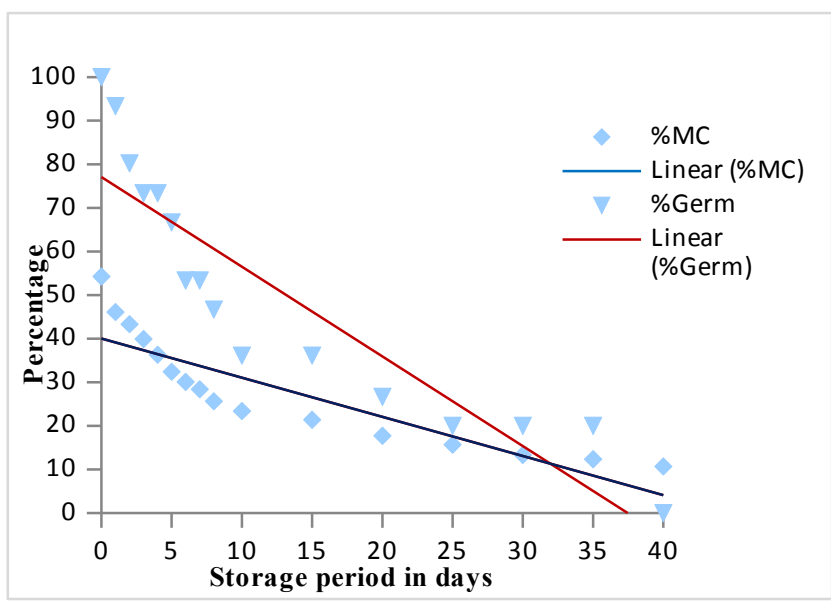

Fig. 4. Closed polyethene bags (200 gauge) at room temperature.

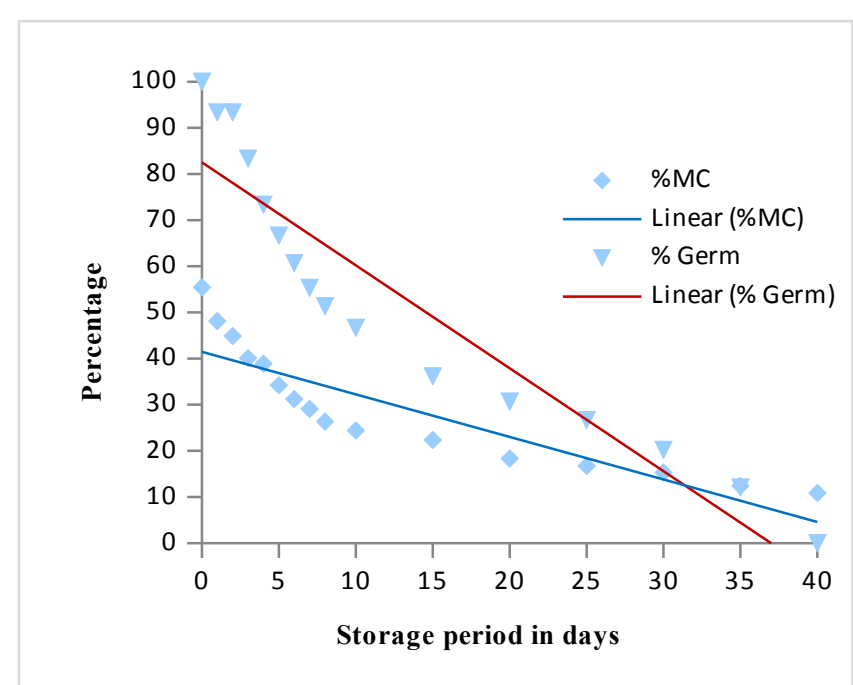

Fig. 5. Closed polyethene bags (400 gauge) at room temperature.

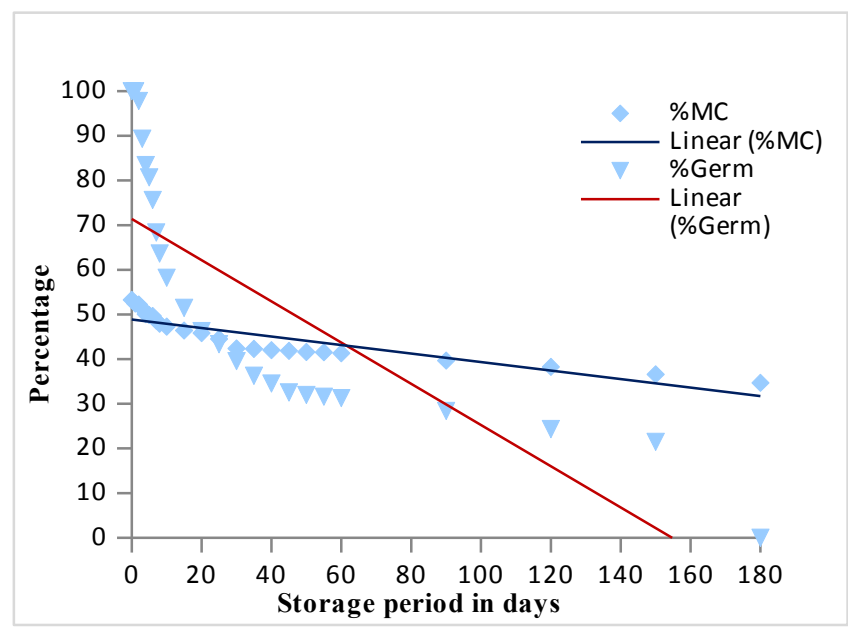

Fig. 6. Closed polycarbonate bottle at $10^{\circ} \mathrm{C}\left(\mathrm{CPBo} 10^{\circ} \mathrm{C}\right)$.

harvest time the moisture content of the seeds were at the range of $53 \%$ to $55 \%$. Seeds stored in open laboratory condition (OPL) recorded a sharp decrease in \% of MC and germination percentage from $53.35 \%$ to $7.39 \%$ and $100 \%$ to 0 within 20 days respectively (Fig. 2). Seeds stored in closed polycarbonate bottles at room temperature (CPBoRT) extended the period of loss of MC\% to 55 days and the seed viability was retained for 50 days which is 30 days more than the open laboratory condition (Fig. 3). In case of seeds stored in closed polyethene bags (200 gauge) at room temperature (CPBg200RT) (Fig. 4) and closed polyethene bags (400 gauge) at room temperature (CPBg400RT) recorded almost similar trend where the loss of MC pattern reached $10.68 \%$ and zero germination on 40 days of storage of seeds (Fig. 5) While the seeds stored at closed polycarbonate bottle and stored at $10{ }^{\circ} \mathrm{C}\left(\mathrm{CPBo} 10^{\circ} \mathrm{C}\right)$ recorded a slower rate of decrease in $\mathrm{MC}$ from $53.24 \%$ at 0 days to $34.68 \%$ on 180 days of storage (Fig. 6). Similarly, the viability of the seeds were also retained till 150 days of storage (21.48\%) (Fig. 6) which was about 10 times greater than that of OPL stored seeds. The pattern of moisture lost and germination against the storage period were analysed statistically by plotting regression graph 
Table 1. Linear regression analysis: Seed germination and \% moisture content as a function of storage days, formula and ' $r$ '.

\begin{tabular}{|c|c|c|c|}
\hline Variable & Formula & Degree of freedom & $\mathbf{r}$ \\
\hline Fig.1 Storage vs Germination & $y=-5.3019 x+90.465$ & $12-2=10$ & $0.9659^{a}$ \\
\hline Fig. 1 Storage vs \% MC & $y=-2.0664 x+42.433$ & $12-2=10$ & $0.9353^{\mathrm{a}}$ \\
\hline Fig.2 Storage vs Germination & $y=-1.5755 x+76.86$ & $19-2=17$ & $0.8981^{\mathrm{a}}$ \\
\hline Fig. 2 Storage vs \% MC & $y=-0.8113 x+49.622$ & $19-2=17$ & $0.9607^{\mathrm{a}}$ \\
\hline Fig.3 Storage vs Germination & $y=-2.057 x+77.072$ & $16-2=14$ & $0.9071^{\mathrm{a}}$ \\
\hline Fig.3 Storage vs \% MC & $y=-0.8984 x+40.035$ & $16-2=14$ & $0.8845^{\mathrm{a}}$ \\
\hline Fig.4 Storage vs Germination & $y=-2.2316 x+82.536$ & $16-2=14$ & $0.9379^{\mathrm{a}}$ \\
\hline Fig.4 Storage vs \% MC & $y=-0.922 x+41.454$ & $16-2=14$ & $0.8871^{\mathrm{a}}$ \\
\hline Fig.5 Storage vs \% MC & $y=-0.0954 x+48.888$ & $24-2=22$ & $0.8883^{\mathrm{a}}$ \\
\hline
\end{tabular}

${ }^{\text {a }}$ ignificance at $0.01 \% \mathrm{p}$ level

and the patterns were significant at $0.01 \% \mathrm{P}$ level (Table 1).

\section{Discussion}

Due to the alarming rate of deforestation and loss of species the potential role of $e x$-situ in conservation of forest genetic resources, as a complement to the widely used in-situ strategies, should be further considered. Despite the urgent need, genetic conservation within the framework of forestry has been slow to develop and $e x$-situ efforts are generally restricted to species and provenances of proven value (15). Knowledge of seed biology is crucial for proper handling including storage of seeds. Seeds shed at relatively high moisture content $(>40-50 \%$ fresh weight) are unable to withstand desiccation and are often sensitive to chilling. These seeds therefore cannot be maintained under conventional seed storage conditions and are described as recalcitrant (16). M. ferrea seeds also fall in this category as the seeds mature with a high moisture content of 53 to $55 \%$ and loss the viability within a short span of 15 days (Fig. 2) in open laboratory condition while in natural condition the seeds lost their viability within 8 days. Of the different conventional methods tried using the polycarbonate bottle and bags, $M$. ferrea seeds retained viability for 150 days with a slow rate of moisture loss from the seeds which are stored in closed polycarbonate bottles at $10{ }^{\circ} \mathrm{C}$ (Fig. 6). In the tested cases the effect of desiccation was though linear but not uniform and initial loss was slow in case of seeds stored in closed poly carbonate bottle both in laboratory condition and at $10{ }^{\circ} \mathrm{C}$. While seeds stored in open laboratory condition the desiccation of the seeds were fast and lost viability of the seeds and within 15 days and MC to $7.39 \%$. On the other hand, seeds stored in polythene bags the rate of desiccation was medium and viability and germination extended up to 40 days (Fig. 4 and 5). In all the treatments, the regression analysis showed a linear inverse relationship, i.e. with the increase in storage $\% \mathrm{MC}$ and $\%$ germination were decreased and the decrease was significant at $0.01 \% \mathrm{P}$ level (Table 1 ).

The above results strongly suggest that fast and moderate desiccation or drying of seeds of $M$. ferrea would be suitable to test the recalcitrant nature of these seeds. Such type of observation was recorded in Quercus nigra (18). In the current study, within 5 days in open laboratory condition approximately $25 \%$ of the MC was lost with $34 \%$ reduction in the germination percentage. While in case of closed polycarbonate bottle loss of \% MC was slower than that of the seeds stored poly bags with different gauges. The importance of seed moisture content alone in maintaining viability becomes fairly evident in seed stored at ambient room temperature. Thus, at ambient room temperature, seeds dehydrated to significantly low moisture content and subsequently maintain at this moisture content in hermetically sealed containers could be an alternative and cheap technology for at least for the short term storage (18). Container form an integral part of seed storage as this provide insulation against moisture and prevent the seed from equilibrating with the ambient relative humidity (19). The results obtained in $M$. ferrea showed that compared to ambient temperature $\left(28 \pm 2{ }^{\circ} \mathrm{C}\right)$, lower temperature helps to retain seed viability potential. But below a certain limit, low temperatures have been reported to cause detrimental effect on seed viability (data not shown) because of its recalcitrant nature. Chilling temperatures have been predominantly found to be detrimental to many recalcitrant seeds of dipterocarps such as Drybalanops aromatica (20), Shorea curtesii, Shorea platycladus (21) Shorea ovalis (22) and Hopea odorata (23). Maintenance of appropriate storage temperature is the only way to contain all three types of damage viz. mechanical damage, metabolism induced damage and macromolecular denaturation during storage of recalcitrant seeds (6). Storage of seeds at low temperature will help to minimize moisture loss (24) thereby preventing mechanical damage and macromolecular damage. Additionally, cold conservation has been reported to prevent oxidative damage which normally happens during storage $(25,26)$. Thus, the most effective and practical way to store intact recalcitrant seeds like $M$. ferrea is by keeping them at low temperature in closed containers wherein the desiccation damages can be minimized or reduced and freezing injury may also be avoided by not using freezing temperatures.

\section{Conclusion}

Seeds of Mesua ferrea are recalcitrant in nature and lose viability with a short span 8-15 days in open condition. Hence, their storage is a problematic one for the conservation and large scale planting. Here, we have standardised a conventional technique whereby the viability of the seeds can be extended to 150-180 days without 
much expenses by storing the seeds in closed polycarbonate bottles at $10^{\circ} \mathrm{C}$. Further refinement of the storage method is in progress to extent the viability of this medicinally important species.

\section{Acknowledgements}

Authors acknowledge Kerala State Council for Science Technology and Environment for the financial assistance as Emeritus Fellowship to PNK and Director KSCSTE-MBGIPS for facilities and encouragements.

\section{Authors' contributions}

PNK and PNS designed the objectives and plan of work, planned the experiment and sanctioned all facilities required. They also helped to set up the experiment. MV carried out the work in the field and laboratory, did all tabulation and calculations. MV and PNK jointly analysed the data and article writing, submission and corrections. All authors provided critical feedback and helped to shape the research system.

\section{Conflict of interests}

The authors declare that they have no competing interest.

\section{References}

1. Anonymous. The Wealth of India. CSIR, New Delhi, India. 1952;3-141.

2. Kar A, Jain SR. Investigations on the antibacterial activity of some Indian indigenous aromatic plants. Flavour Industry. 1971;2:111-13.

3. Mazumder R, Dastidar SG, Basu SP, Mazumder A, Singh SK. Antibacterial potentiality of Mesua ferrea Linn. flowers. Phytotherapy Research: An International Journal Devoted to Pharmacological and Toxicological Evaluation of Natural Product Derivatives. 2004 Oct; 18(10):824-26. https://doi.org/ 10.1002/ptr.1572

4. Chanda S, Rakholiya K, Parekh J. Indian medicinal herb: Antimicrobial efficacy of Mesua ferrea L. seed extracted in different solvents against infection causing pathogenic strains. J Acu Dis. 2013 Jan 1;2(4):27781.https://doi.org/10.1016/S2221-6189(13)60143-2

5. Roberts EH. Predicting the storage life of seeds. Seed Sci Technol. 1973;1:499-514.

6. Umarani R, Kanthaiya AE, Mohamed Faisal $M$ Understanding poor storage potential of recalcitrant seeds. Curr Sci. www.jstor.org/stable/24905571

7. Gebeyaw M. Review on: Impact of seed storage container on seed quality. J Plant Biotechnol Microbiol. 2020;3(1):17 $21 . \quad$ https://www.alliedacademies.org/journal-plantbiotechnology-microbiology/ 17

8. Lavania P, Tiwari A. Effect of storage period, container and temperature on germination in Albizia lebbeck. J Pharm Phytochem. 2019;8(1):2155-57.

9. Khan ML, Bhuyan P, Singh ND, Todaria NP. Fruit set, seed germination and seedling growth of Mesua ferrea (Clusiaceae) in relation to light intensity. J Trop For Sci. 2002 Jan; 1:35-48. https://www.jstor.org/stable/43596205

10. Arunachalam A, Khan ML, Singh ND. Germination, growth and biomass accumulation as influenced by seed size in Mesua ferrea L. Turk. J Bot. 2003 Sep 8; 27(5):343-48.
11. Mithun V, Babu KP, Pradeep NS, Krishnan PN. Phenology and seed development in Mesua ferrea L., a rare medicinal tropical tree species. Trop Plant Res. 2020;7(2):406-14. https://doi.org/10.22271/tpr.2020.v7.i2.048

12. International Seed Testing Association. International rules for seed testing. Rules 1985. Seed Sci Technol. 1985;13(2):299-513.

13. ISTA. International rules for seed testing 2015 . International Seed Testing Association, Bassersdorf, Switzerland. 2015.

14. Sokal RR, Rohlf FJ. Biometry, New York: WH Freeman and Co, 1981 2nd ed.p 584.

15. FAO, Forest resources assessment 1990: Tropical countries. FAO Forestry. Rome: UN Food and Agriculture Organization. 1993; 112.

16. Chin HF, Krishnapillay B. Cryogenic storage of some horticultural species. In IV International Symposium on Seed Research in Horticulture 253. 1988 Sep 5;107112.https://doi.org/10.17660/ActaHortic.1989.253.10

17. Bonner FT. Responses to drying of recalcitrant seeds of Quercus nigra L. Ann Bot. 1996 Aug 1; 78(2):181-87. https://doi.org/10.1006/anbo.1996.0111

18. Phartyal SS, Joshi G, Thapliyal R. Storage of Himalayan maple (Acer caesium) seed: A threatened tree species of the Central Himalayas. Seed Sci Technol. 2003;31:149-59. https://doi.org/10.15258/sst.2003.31.1.15

19. Willan RL. A guide to forest seed handling with special reference to tropic, FAO, Forestry Paper Rome. 1985.

20. Janzen DH. Seed predation by animals. Ann Rev Ecol Sys. 1971 Nov; 2(1):465-92.

21. Tang HT. Preliminary tests on the storage and collection of some Shorea species seeds. Malay Forest. 1971.

22. Sasaki S. Storage and germination of Dipterocarp seeds. Malays Forester. 1980;43:290-308.

23. Tang HT, Tamari C. Seed description and storage tests of some Dipterocarps. Malays Forester.1973;36(2).

24. Berjak P, Pammenter NW. From Avicennia to Zizania: seed recalcitrance in perspective. Ann Bot. 2008;101:213-23. https://doi.org/10.1093/aob/mcm168

25. Hendry GAF, Finch-SavageWE, Thorpe PC, Atherton NM, Buckland SM, Nilsson KA,SeelWE. Freeradical processes and loss of seed viability during desiccation in the recalcitrant species Quercus robur L. New Phytol. 1992; 122: 273-79. https://doi.org/10.1111/j.1469-8137.1992.tb04231.x

26. Leprince O, Atherton NM, Deltour R, Hendry GAF. The involvement of respiration free radical processes during loss of desiccation tolerance in germinating Zea mays L. an electron paramagnetic resonance study. Plant Physiol. 1994;104:1333-39. https://doi.org/10.1104/pp.104.4.1333

Additional information

Peer review information: Plant Science Today thanks Sectional Editor and the other anonymous reviewers for their contribution to the peer review of this work.

Reprints and permissions information is available at

https://horizonepublishing.com/journals/index.php/PST/open_access_policy

Publisher's Note: Horizon e-Publishing Group remains neutral with regard to jurisdictional claims in published maps and institutional affiliations.

To cite this article: Mithun V, Pradeep NS, Krishnan P N. Seed storage studies in Mesua ferrea $\mathrm{L}$. a medicinal tree of Indo-Malayan region. Plant Science Today. 2021;8(3):712-716. https://doi.org/10.14719/pst.2021.8.3.1180

Plant Science Today, published by Horizon e-Publishing Group, is covered by Scopus, Web of Science, BIOSIS Previews, Clarivate Analytics, etc. See https://horizonepublishing.com/journals/index.php/PST/indexing_abstracting 